DIL, Gabriel; GALLAS, Mirelle. A (i)legitimidade de atuação dos governos estaduais e municipais para o combate ao covid-19. Revista Eletrônica Direito e Política, Programa de Pós-Graduação Stricto Sensu em Ciência Jurídica da UNIVALI, Itajaí, v.15, n.2, 20 quadrimestre de 2020. Disponível em: www.univali.br/direitoepolitica - ISSN 1980-7791

\title{
A (I)LEGITIMIDADE DE ATUAÇÃO DOS GOVERNOS ESTADUAIS E MUNICIPAIS PARA O COMBATE AO COVID-19
}

\author{
THE STATE LEGITIMACY OF STATE AND MUNICIPAL GOVERNMENTS
}

TO COMBAT COVID-19

\author{
Gabriel Dil ${ }^{1}$ \\ Mirelle Gallas ${ }^{2}$
}

\section{RESUMO}

A pandemia mundial da Covid-19 colocou o Brasil em estado de emergência, exigindo a tomada de decisões rápidas e extremas pelo poder executivo, nos vários níveis da federação. Em que pese as inúmeras medidas tomadas tenham respaldo da Organização Mundial da Saúde, passou-se a perceber uma guerra política que levou a discussão quanto à legitimidade da atuação dos entes federados. Analisa-se, portanto, a competência dos entes federados para a tomada de decisões que visem a proteção ao direito à saúde, o que foi objeto de recente decisão na Ação Direta de Inconstitucionalidade no 6.341, proposta pelo Partido Democrático Trabalhista, perante o Supremo Tribunal Federal.

PALAVRAS-CHAVE: entes federados, competência, direito à saúde, pandemia.

\section{ABSTRACT}

The global pandemic of Covid-19 has put Brazil in a state of emergency, requiring the decision-making of swift and extreme decisions by the executive branch, at various levels of the federation. In spite of the countless measures taken to be supported by the World Health Organization, a political war began to be perceived that led to the discussion regarding the legitimacy of the actions of the federated entities. Therefore, the competence of federated entities to make decisions aimed at protecting the right to health is analyzed, which was the subject of a recent decision in Direct

\footnotetext{
${ }^{1}$ Mestrando em Direito na linha Jurisdição Constitucional e Democracia na Universidade de Passo Fundo, com bolsa CAPES (modalidade II). Especialista em Ciências Criminais pela Universidade Estácio de Sá do Rio de Janeiro/RJ. Pós-graduando em Direito Médico pela Faculdade CERS. Graduado em Ciências Jurídicas e Sociais pela Universidade de Passo Fundo. Advogado inscrito na OAB/RS sob o no 111.168 . Email: adv.gabrieldil@gmail.com. Fone: (54) 9 9616-4499.

2 Mestranda em Direito pelo Programa de Pós-Graduação, Mestrado em Direito da Universidade de Passo Fundo/RS; Especialista em Direito Processual Civil e Constitucional pela Universidade de Passo Fundo/RS; Advogada inscrita na OAB/RS sob no 51.924. Graduada em Direito pela Universidade de Passo Fundo/RS. E-mail: mirellegallas@gmail.com. Fone: (54) 9 9998-9051.
} 
DIL, Gabriel; GALLAS, Mirelle. A (i)legitimidade de atuação dos governos estaduais e municipais para o combate ao covid-19. Revista Eletrônica Direito e Política, Programa de Pós-Graduação Stricto Sensu em Ciência Jurídica da UNIVALI, Itajaí, v.15, n.2, 20 quadrimestre de 2020. Disponível em: www.univali.br/direitoepolitica - ISSN 1980-7791

Unconstitutionality Action No. 6,341, proposed by the Democratic Labor Party, before the Supreme Court Federal.

KEYWORDS: federated entities, competence, right to health, pandemic.

\section{INTRODUÇÃO}

No presente artigo será analisada a competência dos entes federados para a tomada de decisões acerca de medidas sanitárias necessárias à proteção da saúde da população brasileira em razão da pandemia do Covid-19. Para tanto, utiliza-se do método dedutivo, através de pesquisa bibliográfica e legislativa, a fim de referenciar os elementos que dão ensejo às competências e às medidas sanitárias que assegurem o direito à saúde.

No primeiro capítulo será analisado o federalismo e a formatação cooperativa da federação brasileira, a partir da Constituição de 1988 que define competências específicas dos seus entes.

O segundo capítulo analisa o direito à saúde constitucionalmente garantido, bem como as medidas sanitárias adotadas pelo poder estatal, em vários níveis da federação, necessárias à contenção da disseminação do vírus.

O terceiro capítulo versa sobre a discussão judicial e política acerca da competência dos entes federativos para a tomada de decisões urgentes acerca de medidas sanitárias, com ênfase na análise da Ação Direta de Inconstitucionalidade no 6.341, proposta pelo Partido Democrático Trabalhista, perante o Supremo Tribunal Federal, no dia 23 de março de 2020.

\section{O FEDERALISMO E AS COMPETÊNCIAS DOS ENTES FEDERADOS NA CONSTITUIÇÃO DA REPÚBLICA FEDERATIVA DO BRASIL DE 1988}

A teoria do sistema federativo, segundo Proudhon, pressupõe uma ordem política com dois princípios contrários que fazem parte da natureza e do espírito da sociedade: a autoridade e a liberdade. Em todos os sistemas, incluindo no federalismo, o que se 
DIL, Gabriel; GALLAS, Mirelle. A (i)legitimidade de atuação dos governos estaduais e municipais para o combate ao covid-19. Revista Eletrônica Direito e Política, Programa de Pós-Graduação Stricto Sensu em Ciência Jurídica da UNIVALI, Itajaí, v.15, n.2, 20 quadrimestre de 2020. Disponível em: www.univali.br/direitoepolitica - ISSN 1980-7791

busca é o equilíbrio desses princípios. Em uma sociedade organizada o crescimento deve ser contínuo com a autoridade em recuo e o avanço da liberdade sem que colidam. Para equalizar esses aspectos tão contraditórios e ao mesmo tempo complementares de autoridade e liberdade, nasce a ideia de contrato político, o que Proudhon denomina federação. ${ }^{3}$

Esse contrato político necessita duas condições: ser sinalagmático e comutativo, e contido dentre certos limites. Ou seja, para o cidadão que realiza a contratação deverá receber do Estado o equivalente ao que sacrifica e ainda, conservar sua liberdade, autonomia e iniciativa, sendo essas garantidas pelo Estado. O sistema federativo é o oposto de hierarquia ou centralização administrativa e governamental. ${ }^{4}$

Zimmermann compreende o federalismo sobre três pilares fundamentais que são: a descentralização política, o pluralismo federativo e o princípio da subsidiariedade. A descentralização política garante autoridade e recursos aos governos regionais ou locais, possibilitando um equilíbrio federativo, a redistribuição de recursos e a maior participação dos cidadãos a fim de garantir o cumprimento das normas, impedir comportamentos arbitrários, garantir a efetivação de direitos fundamentais e um maior equilíbrio entre a autoridade e liberdade. ${ }^{5}$

O pluralismo federativo, por sua vez, deve ser fundamentado nos interesses regionais, possibilitando a transformação democrática, através do atendimento das diversidades regionais. Para tanto as unidades políticas devem criar suas próprias leis a fim de concretizar o federalismo democrático.

A subsidiariedade busca a redefinição das práticas governamentais, estabelecendo limites para a ingerência do poder público. Nos traz o ideário das instâncias políticas descentralizadas desempenharem uma maior parte das atividades, com igual ou maior grau de eficiência que o poder central, mantendo-se neste atribuições subsidiárias. As unidades menores atendem o que podem fazer por si, no caso o ente local, o

\footnotetext{
${ }^{3}$ PROUDHON, Pierre- Joseph. Do princípio federativo e da necessidade de reconstruir o partido da revolução. Lisboa: Colibri, 1996.Tradução: Francisco Trindade. p. 40-42.

${ }^{4}$ PROUDHON, Pierre- Joseph. Do princípio federativo e da necessidade de reconstruir o partido da revolução. p. 44.
}

${ }^{5}$ ZIMMERMANN, Augusto. Teoria geral do federalismo democrático. 2. ed. Rio de Janeiro: Lumen Juris, 2005. Capítulos 7, 8 e 9. 
DIL, Gabriel; GALLAS, Mirelle. A (i)legitimidade de atuação dos governos estaduais e municipais para o combate ao covid-19. Revista Eletrônica Direito e Política, Programa de Pós-Graduação Stricto Sensu em Ciência Jurídica da UNIVALI, Itajaí, v.15, n.2, 20 quadrimestre de 2020. Disponível em: www.univali.br/direitoepolitica - ISSN 1980-7791

Município. ${ }^{6}$ Segundo Corralo, a subsidiariedade e a não centralização "conduzem ao princípio da liberdade, identificada com a autonomia ou autodeterminação, elementos essenciais a qualquer ente federativo." ${ }^{7}$

Mas há distinção entre o federalismo e a federação. O federalismo está embasado no Estado democrático de direito, democracia, república, não centralização, subsidiariedade e pluralismo. A federação é a concretização desses princípios "numa determinada realidade geográfica". ${ }^{8}$ O Autor nos ensina.

Federalismo e federação são termos distintos, porém, no decorrer da maior parte da história humana foram tratados como sinônimos. É a partir do século XX que se compreende 0 federalismo como um conjunto de princípios e ideias que buscam a unidade na diversidade, aplicando-se de diversas formas na realidade fática, na qual a federação é uma das possibilidades. ${ }^{9}$

Reali analisa a as virtudes e riscos do federalismo ponderando ser benéfico o fato de um mesmo partido político não governar vários Estados, possibilitando, portanto, unidades autônomas de poder, compondo de forma harmoniosa os valores locais e nacionais, através da maior correlação entre a União e os governos estaduais. Suscita a importância da forma de organização federativa a fim de se estabelecer a "unidade na diversidade ${ }^{10}$, e assim dispõe.

A organização federativa é a única compatível com países, como o nosso, de imenso território, sem o que se descamba para a perniciosa centralização unitária do poder, com olvido ou desprezo de imensas peculiaridades regionais. Todavia, o federalismo pressupõe o mais apurado senso de responsabilidade,

\footnotetext{
${ }^{6}$ ZIMMERMANN, Augusto. Teoria geral do federalismo democrático.

7 CORRALO, Giovani da Silva. Dimensões do poder : as federações e os direitos fundamentais. Justiça do Direito, Passo Fundo , 2011 v. 25 n. 2 Disponível em: <http://seer.upf.br/index.php/rjd/article/view/4001> Acesso em: 31 mar. 2020. p. 32.

${ }^{8}$ CORRALO, Giovani da Silva. Dimensões do poder : as federações e os direitos fundamentais. $p$. 31-32.

9 CORRALO, Giovani da Silva. O poder municipal na federação brasileira: reflexão sobre a autonomia municipal e o federalismo. História : Debates e Tendências, Passo Fundo , v. 15 n. 1 , 2015. Disponível em: <http://seer.upf.br/index.php/rhdt/article/view/5281> . Acesso em 31 mar. 2020. p. 136.

${ }^{10}$ REALE, Miguel. Virtudes e riscos do federalismo. p. 18-19. In: Política e direito. São Paulo: Saraiva, 2006. Disponível em: <https://integrada.minhabiblioteca.com.br/\#/books/9788502137691/cfi/28!/4/4@0.00:0.00>. Acesso em: 31 mar. 2020.
} 
DIL, Gabriel; GALLAS, Mirelle. A (i)legitimidade de atuação dos governos estaduais e municipais para o combate ao covid-19. Revista Eletrônica Direito e Política, Programa de Pós-Graduação Stricto Sensu em Ciência Jurídica da UNIVALI, Itajaí, v.15, n.2, 20 quadrimestre de 2020. Disponível em: www.univali.br/direitoepolitica - ISSN 1980-7791

com lideranças políticas que aliem aos conhecimentos econômicofinanceiros e administrativos a consciência ética essencial à gestão da coisa pública. ${ }^{11}$

O federalismo no Brasil, segundo Moreira Neto, foi

inspirado no protótipo de descentralização espacial do poder, como instituído na Constituição dos Estados Unidos da América, foi concebido como técnica de separação de centros de poder para reduzir os inconvenientes de uma excessiva concentração em um só ente político, flexibilizando-os de modo a atenderem às peculiaridades regionais de países com grandes territórios, como o subcontinente brasileiro ${ }^{12}[\ldots]$

A federação tem por característica reunir vários estados-membros autônomos a um poder central soberano. O federação como forma de estado foi estabelecida no Brasil a partir da proclamação da República em 1889 e adotada na primeira Constituição republicana em 1891, sendo mantida nas demais Constituições, com exceção do período do Estado Novo, sob a égide da Constituição de 1937.

O artigo 60, § $4^{\circ}$ da Constituição Federal de 1988 estabelece a forma federativa de Estado como uma cláusula pétrea. Moreira Neto caracteriza a federação assim dizendo.

A existência de uma federação, que na sintética expressão de Paulino Jacques é um "Estado de Estados", depende de uma nítida distribuição de competências, de modo que se defina claramente o que compete ao Poder Central (a União), aos Estados-Membros (ou simplesmente Estados, Províncias, Cantões, etc.) e, no caso brasileiro, também ao Distrito Federal e aos Municípios, pois que constituem unidades federadas sui generis. ${ }^{13}$

Nas federações a distribuição do poder governamental é realizada em unidades regionais. Em sua maioria, a distribuição do poder sobre o território ocorre em duas unidades: a central e as regionais (União e Estados federados). No Brasil, os

\footnotetext{
${ }^{11}$ REALE, Miguel. Virtudes e riscos do federalismo. p. 19.

12 MOREIRA NETO, Diogo de Figueiredo. Curso de Direito Administrativo. 16. ed. Rio de janeiro: Forense, 2014. p. 35.

13 MOREIRA NETO, Diogo de Figueiredo. Curso de Direito Administrativo. p. 34.
} 
DIL, Gabriel; GALLAS, Mirelle. A (i)legitimidade de atuação dos governos estaduais e municipais para o combate ao covid-19. Revista Eletrônica Direito e Política, Programa de Pós-Graduação Stricto Sensu em Ciência Jurídica da UNIVALI, Itajaí, v.15, n.2, 20 quadrimestre de 2020. Disponível em: www.univali.br/direitoepolitica - ISSN 1980-7791

Municípios integram essa categoria de ente federado autônomo, dotado de organização e governo próprios, bem como de competências exclusivas, portanto, possui três esferas governamentais, além do Distrito Federal, também dotado de autonomia. ${ }^{14}$

A Federação brasileira constitui-se em uma forma de distribuição de poderes ou competências. Essa descentralização política através de uma repartição de competências demonstra a recepção da subsidiariedade no ordenamento jurídico brasileiro. ${ }^{15}$ Baracho aduz que

o dinamismo do federalismo, relacionado com o princípio da subsidiariedade, leva à correlação entre integração e autonomia, criando uma espécie de subsidiariedade de base federativa, capaz de assegurar paz e liberdade dos diversos Estados que fazem parte do processo aproximativo geral, com preservação das potencialidades individuais. ${ }^{16}$

Moreira Neto considera uma evolução do federalismo brasileiro a formulação de políticas integradas de desenvolvimento regional que se destinam ao atendimento de áreas territoriais com características geo-socioeconômicas, homogêneas e que independem da divisão políticas, conforme incumbência da União prevista no art. 21, IX da Constituição Federal, denominado na Seção intitulada "Das Regiões", conforme o art. 43 do mesmo diploma. O estabelecimento de regiões metropolitanas, aglomerações urbanas e microrregiões, mediante pactos de coordenação entre entes públicos consagra atividades de interesse público visando o desenvolvimento regional. Contudo, o Autor reflete acerca do modelo "in fieri de federalismo brasileiro". ${ }^{17}$

Em nossa Constituição Federal, a competência própria da União está estabelecida nos artigos 21 e 22. As competências comuns a todos os entes encontram previsão no artigo 23. No artigo 24 estão dispostas as competências concorrentes entre a União,

\footnotetext{
${ }^{14}$ SILVA, José Afonso da. Curso de direito constitucional positivo. 39. ed. São Paulo: Malheiros, 2016. P. 640.

15 TORRES, Silvia Faber. O princípio da subsidiariedade no direito público contemporâneo. Rio de Janeiro: Renovar, 2001. p. 242.

${ }^{16}$ BARACHO, José Alfredo de Oliveira. O princípio da subsidiariedade: conceito e evolução. Rio de Janeiro: Forense, 2003. p. 46.

17 MOREIRA NETO, Diogo de Figueiredo. Curso de Direito Administrativo. p. 36-37.
} 
DIL, Gabriel; GALLAS, Mirelle. A (i)legitimidade de atuação dos governos estaduais e municipais para o combate ao covid-19. Revista Eletrônica Direito e Política, Programa de Pós-Graduação Stricto Sensu em Ciência Jurídica da UNIVALI, Itajaí, v.15, n.2, 20 quadrimestre de 2020. Disponível em: www.univali.br/direitoepolitica - ISSN 1980-7791

Estados e Distrito Federal. A competência dos Estados está prevista no artigo 25. As competências expressas dos municípios estão dispostas no artigo 30 da Constituição.

Observa-se que entre as competências comuns cabíveis a todos os entes federados está prevista no artigo 23, sendo no inciso II - cuidar da saúde e assistência pública, da proteção e garantia das pessoas portadoras de deficiência. Ainda, está disposto no parágrafo único do referido artigo que serão fixadas normas por meios de Leis complementares para a cooperação entre a União e os Estados, o Distrito Federal e os Municípios, tendo em vista o equilíbrio do desenvolvimento e do bem-estar em âmbito nacional, conforme redação dada pela Emenda Constitucional n 53, de 2006.

Considerando as competências comuns ou concorrentes dos entes federados identifica-se a existência de um federalismo cooperativo, sobretudo considerando a disposição dada pela Emenda complementar 53/2006 que estabelece a fixação de normas para a cooperação entre eles através de leis complementares, tendo em vista o equilíbrio do desenvolvimento e do bem-estar em âmbito nacional.

É razoável o entendimento que essas leis complementares sejam editadas pela União. Poderá no entanto, observadas determinadas circunstâncias e da matéria em causa, atendendo o critério de proporcionalidade, quando se trata de direitos fundamentais, exemplificando nisso o direito à saúde, que se dê preferência à legislação e ações mais próximas da pessoa e do meio que vive. Exsurge dois aspectos quanto a isso, orientados pelo STF, o primeiro refere-se a impossibilidade de renúncia da competência legislativa e o segundo, que os entes da federação estão limitados a legislar sobre as matérias que Ihes competem. ${ }^{18}$ Nesse sentido esclarece,

a despeito da eventual regulamentação legislativa do modo de cooperação, 0 exercício das competências comuns frequentemente gera conflitos entre os entes federativos, conflito este que, na acepção de André Ramos Tavares, deve ser resolvido aplicando-se a orientação geral decorrente do princípio do interesse prevalente, cientes das limitações inerentes a tal princípio. De todo modo, esta tem sido também a orientação adotada pelo STF, que, partindo da correta premissa de que inexiste hierarquia entre os entes federativos, invoca uma hierarquia de interesses, a partir do interesse mais geral

18 SARLET, Ingo Wolfgang; MARINONI, Luiz Guilherme; MITIDIERO, Daniel. Curso de direito constitucional. 7. ed. São Paulo: Saraiva Educação, 2018, p. 968-970. 
DIL, Gabriel; GALLAS, Mirelle. A (i)legitimidade de atuação dos governos estaduais e municipais para o combate ao covid-19. Revista Eletrônica Direito e Política, Programa de Pós-Graduação Stricto Sensu em Ciência Jurídica da UNIVALI, Itajaí, v.15, n.2, 20 quadrimestre de 2020. Disponível em: www.univali.br/direitoepolitica - ISSN 1980-7791

(nacional) da União, no sentido de que este há de preferir ao interesse mais restrito dos Estados ou então dos Municípios. ${ }^{19}$

No que condiz com a efetivação do direito à saúde, a Constituição Federal estabeleceu entre as competências concorrentes dos entes federativos a participação financeira e executora de ações e prestações de serviços em saúde.

\section{O DIREITO FUNDAMENTAL À SAÚdE E A ATUAÇÃO DOS ENTES FEDERADOS NO COMBATE A PANDEMIA DA COVID-19}

A concretização do direito à saúde é um dever de todos, a ser executado de forma descentralizada pelo Estado, mediante a coordenação entre os entes federados, visando a maximização das ações para sua efetivação.

Cumpre mencionar que o entendimento de saúde vai muito além da ausência de enfermidades, devendo ser visto de forma mais abrangente. Nesse aspecto, Pilau Sobrinho define saúde como: "o direito individual-coletivo da pessoa humana, fazendo a promoção e prevenção, visando a redução da complexidade da doença e primando pela qualidade de vida". ${ }^{20}$

A partir do projeto de reforma sanitária desenvolvido pelo chamado movimento sanitarista, fortalecido na década de 80, os constituintes da Constituição Federal de 1988 aprovaram algumas das propostas do movimento passando a inserir na Carta Magna princípios para o desenvolvimento da saúde no Brasil, entre eles: a universalização da saúde e não discriminação no atendimento; a relevância pública das ações e serviços e competência do poder público regulamentar e fiscalizar ações, mesmo quando realizadas por entes privados; o estabelecimento de um sistema

19 SARLET, Ingo Wolfgang; MARINONI, Luiz Guilherme; MITIDIERO, Daniel. Curso de direito constitucional. p. 969.

20 PILAU SOBRINHO, Liton Lanes. Direito à saúde: uma perspectiva constitucionalista. Passo Fundo: UPF, 2003. In: ALVES, Paulo Roberto Ramos; PILAU SOBRINHO, Liton Lanes; MORANDINI, Jaqueline. Do constitucionalismo sanitário ao Estatuto do Idoso: o direito à saúde como aquisição evolutiva e suas formas de efetivação = Of the sanitary constitutionalism of the Elderly Statute: the right to the health as evolutionary acquisition and their effectuate forms. Revista Brasileira de Ciências do Envelhecimento Humano, Passo Fundo, v.5, n.2, p. 141-149, jul./dez. 2008. Disponível em: <http://www.upf.br/seer/index.php/rbceh/article/view/345/255>. Acesso em: 02 Abr. 2020. 
DIL, Gabriel; GALLAS, Mirelle. A (i)legitimidade de atuação dos governos estaduais e municipais para o combate ao covid-19. Revista Eletrônica Direito e Política, Programa de Pós-Graduação Stricto Sensu em Ciência Jurídica da UNIVALI, Itajaí, v.15, n.2, $2^{\circ}$ quadrimestre de 2020. Disponível em: www.univali.br/direitoepolitica - ISSN 1980-7791

unificado de saúde, integrado e hierarquizado, descentralizado e com a participação da comunidade; participação do setor privado, em regime complementar, mediante repasse de recursos públicos para subvenção de entidades sem fins lucrativos; e, proibição de sangue humano e seus derivados. ${ }^{21}$

Na década de 90, em que pese a aprovação da Lei nº 8.080 de 1990, denominada a Lei Orgânica da Saúde, iniciou-se um processo de esvaziamento das políticas públicas em saúde, transferindo grande parte de suas responsabilidades à sociedade, desenvolvendo apenas o papel promotor e regulador das políticas, mediante incentivo da esfera pública não estatal, através das entidades sem fins lucrativos e filantrópicas. ${ }^{22}$

No artigo 196 da Constituição Federal, a saúde é estabelecida como um dever de todos e do Estado, mediante a garantia de políticas públicas sociais e econômicas para possibilitar a redução do risco de doenças, o acesso igualitário e universal à sua promoção, proteção e recuperação. Para consecução dessas garantias, a Constituição prevê a prestação colaborativa e coordenada e a participação financeira dos entes federados.

Ainda, no artigo 197 da Constituição Federal está contida a relevância pública de ações e serviços de saúde corroborando ao entendimento da primazia da saúde, entre outros direitos como alimentação, educação e moradia, como componente necessário à promoção do bem estar social e a dignidade da pessoa humana. Para concretização de tal direito cabe ao Poder Público a regulamentação, fiscalização e controle das ações e serviços através dos entes federados ou através de pessoa física ou jurídica de direito privado.

Essas ações e serviços públicos de saúde integram o Sistema Único de Saúde. - SUS, financiado com recursos do orçamento da seguridade social, da União, dos Estados, do Distrito Federal e dos Municípios, entre outros, mediante as características de descentralização, atendimento integral, contínuo e participação da comunidade, tal qual preconiza o artigo $4^{\circ}$ da Lei no 8080/1990 (Lei Orgânica da Saúde - LOS). Diante disso, é corroborada a descentralização político-administrativa, por meio da

\footnotetext{
${ }^{21}$ SIMÕES, Carlos. Curso de direito de serviço social. 2.ed. São Paulo: Cortez, 2008, p. 126-127.

22 SIMÕES, Carlos. Curso de direito de serviço social. p. 128.
} 
DIL, Gabriel; GALLAS, Mirelle. A (i)legitimidade de atuação dos governos estaduais e municipais para o combate ao covid-19. Revista Eletrônica Direito e Política, Programa de Pós-Graduação Stricto Sensu em Ciência Jurídica da UNIVALI, Itajaí, v.15, n.2, 20 quadrimestre de 2020. Disponível em: www.univali.br/direitoepolitica - ISSN 1980-7791

participação de estados e municípios na prestação dos serviços e das ações de saúde, através de uma redistribuição de poder, das competências e dos recursos.

Ademais, quando há ameaça iminente à saúde pública, as autoridades de todas as esferas do poder, não devem medir esforços para proteger a população e manter o funcionamento pleno do sistema de saúde, para que toda pessoa que venha necessitar de atendimento, possa encontrar resposta e acolhimento por parte do Estado. Ainda, considerando que o direito à saúde é um direito fundamental, é dever de todos os entes federados protegê-lo e garanti-lo a população, tanto em situações de normalidade, quanto em ocasiões emergenciais.

A emergência sanitária internacional causada pela pandemia da Covid-19, coloca em prova o sistema de saúde brasileiro. No entanto, antes de adentrar ao tema, insta frisar que a pandemia da Covid-19 teve início na China, no segundo semestre de 2019. Trata-se de um novo vírus, com alta letalidade, de propagação rápida, e que ainda inexistem estudos conclusivos acerca de uma eventual cura. A doença se espalhou no Brasil entre os meses de janeiro e março de 2020, período em que a Organização Mundial da Saúde passou a tratar a Covid-19 como pandemia.

Outrossim, até se chegar ao conceito do que seja uma pandemia, deve-se analisar a cadeia terminológica que conduz até ela. Nesse sentido, optou-se por iniciar procedendo a diferenciação entre epidemia e endemia. A primeira se distingue da segunda por se caracterizar pela incidência, em curto lapso temporal, com grande número de casos de uma doença. Já a segunda, consiste em um menor número de casos no decorrer de um longo período de tempo ${ }^{23}$.

Há que se salientar que uma endemia é uma doença mais peculiar a um determinado povo, país ou região. De modo contrário, e mais amplo, o termo pandemia tem origem grega, e foi utilizado por Platão no sentido da palavra significar qualquer acontecimento capaz de alcançar toda a população. Assistia razão o filósofo, uma vez

${ }^{23}$ REZENDE, JM DE. EPIDEMIA, ENDEMIA, PANDEMIA, EPIDEMIOLOGIA. Revista de Patologia Tropical / Revista de Patologia Tropical , v. 27, n. 1, 11. p. 153-155. 
DIL, Gabriel; GALLAS, Mirelle. A (i)legitimidade de atuação dos governos estaduais e municipais para o combate ao covid-19. Revista Eletrônica Direito e Política, Programa de Pós-Graduação Stricto Sensu em Ciência Jurídica da UNIVALI, Itajaí, v.15, n.2, 20 quadrimestre de 2020. Disponível em: www.univali.br/direitoepolitica - ISSN 1980-7791

que o conceito moderno de pandemia é uma epidemia que se espalha em grandes proporções, afetando várias nações e a mais de um continente ${ }^{24}$.

Sendo assim, quando surge uma nova doença em determinado lugar do mundo, é procedida uma análise acerca do nível de letalidade e da capacidade/velocidade de proliferação da patologia. Essa análise é procedida por alguns órgãos internacionais especializados em saúde, como é o caso da Organização Mundial da Saúde.

A Organização Mundial de Saúde (OMS), é uma agência especializada das Nações Unidas, que se destina às questões de saúde. Com fundação em 07 de abril de 1948, a agência objetiva garantir o acesso a saúde a todos os seres humanos. Igualmente, "Seu propósito primordial é a consecução, por parte de todos os povos, dos mais altos padrões de saúde possíveis"25.

A agência de saúde das Nações Unidas emitiu alertas e recomendações aos países que já possuíam casos de coronavírus confirmados, bem como indicou quais condutas cada chefe de Estado deveria tomar, como atuação preventiva, nos países que ainda não haviam casos confirmados, mas que em curto espaço de tempo também estariam sendo afetados pela pandemia ${ }^{26}$. Posteriormente, com os avanços da pandemia no Brasil, os governadores estaduais e prefeitos começaram a se articular e se preparar para dar suporte e fortalecer o sistema de saúde local, a fim de garantir o acesso à saúde as futuras vítimas da Covid-1927.

Os estados e municípios decretaram medidas restritivas, proibindo o acesso a praias, fechando shoppings e comércios considerados não essenciais, estabelecendo pena de multa a quem viesse a descumprir as medidas estabelecidas pelo governo, a fim de

\footnotetext{
${ }^{24}$ REZENDE, JM DE. EPIDEMIA, ENDEMIA, PANDEMIA, EPIDEMIOLOGIA. p. 153-155.

25 O que é a OMS? Organização Pan-Americana da Saúde. Universidade de São Paulo - USP. Biblioteca Virtual de Direitos Humanos. Disponível http://www.direitoshumanos.usp.br/index.php/OMS-Organiza\%C3\%A7\%C3\%A3o-Mundial-daSa\%C3\%BAde/o-que-e-a-oms.html. Acesso em: 10 abr. 2020.

26 GÜELL, Oriol. OMS declara alerta internacional diante da expansão incontrolável do coronavírus. El País, Barcelona, Espanha, 30 de jan. de 2020. Disponível em: https://brasil.elpais.com/sociedade/202001-30/oms-declara-alerta-internacional-diante-da-expansao-incontrolavel-do-coronavirus.html. Acesso em: 23 abr. 2020.

27 OLIVEIRA, Marcelo; SABÓIA, Gabriel. Quarentena em São Paulo e no Rio: O que você pode e o que não pode fazer. UOL, São Paulo/SP, 25 de mar. de 2020 . Disponível em: https://noticias.uol.com.br/saude/ultimas-noticias/redacao/2020/03/25/quarentena-em-sao-paulo-oque-voce-pode-e-o-que-nao-pode-fazer.htm. Acesso em: 22 abr. 2020.
} 
DIL, Gabriel; GALLAS, Mirelle. A (i)legitimidade de atuação dos governos estaduais e municipais para o combate ao covid-19. Revista Eletrônica Direito e Política, Programa de Pós-Graduação Stricto Sensu em Ciência Jurídica da UNIVALI, Itajaí, v.15, n.2, 20 quadrimestre de 2020. Disponível em: www.univali.br/direitoepolitica - ISSN 1980-7791

evitar a velocidade de propagação do vírus e com isso proteger o sistema de saúde de um eventual colapso. No Rio Grande do Sul, o governador Eduardo Leite, por meio do Decreto no 55.154, no dia $1^{0}$ de abril de 2020, reiterou a declaração de estado de calamidade pública em todo o território estadual, bem como determinou medidas emergenciais de prevenção e enfrentamento à pandemia da Covid-1928.

No município de Passo Fundo/RS, antes do governo estadual estabelecer medidas mais rígidas, o prefeito Luciano Azevedo publicou o Decreto no 32/2020, no dia 19 de março de 2020, decretando situação de emergência no município e determinando o fechamento de quaisquer estabelecimentos comerciais e de serviços que não estivessem expressamente previstos para atender necessidades básicas da população ${ }^{29}$.

O comportamento autônomo das autoridades de norte a sul do Brasil, no que tange a promoção e fortalecimento da saúde pública tem se assemelhado muito. A atuação positiva de governadores e prefeitos neste período pandêmico leva a uma série de condutas inovadoras e inteligentes, como é o caso do governador do estado do Maranhão - Flávio Dino -, que efetuou a compra de máscaras e respiradores da China, em "uma verdadeira operação de guerra para levar ao estado, em tempo recorde, 107 respiradores e 200 mil máscaras". A operação comandada por Flávio Dino, envolveu 30 pessoas, e "foi traçada para evitar que o lote fosse desviado ou vendido aos Estados Unidos ou confiscado por Jair Bolsonaro - como já havia acontecido outras vezes, segundo a coluna Painel, da Folha de S. Paulo" ${ }^{30}$.

Em entrevista à Folha de São Paulo, o governador do Maranhão disse que "Se não fizéssemos dessa forma, demoraríamos três meses para conseguir essa quantidade de

\footnotetext{
28 RIO GRANDE DO SUL (Estado). Decreto no 55.154, de $1^{0}$ de abril de 2020, Palácio Piratini, Porto Alegre/RS. Disponível em: https://estado.rs.gov.br/upload/arquivos//decreto-55-154-01abr2020.pdf. Acesso em: 22 abr. 2020.

29 PASSO FUNDO (Município). Decreto no 32, de 19 de março de 2020, Prefeitura de Passo Fundo, Passo Fundo/RS. $\quad$ Disponível http://www.pmpf.rs.gov.br/servicos/geral/multimidia/decreto_32_2020_coronavirus_20032020.pdf. Acesso em: 22 abr. 2020.

30 Governador do Maranhão dribla Governo Federal e compra máscaras da China. Correio Braziliense. Brasília/DF, 16 de abr. de $2020 . \quad$ Disponível https://www.correiobraziliense.com.br/app/noticia/brasil/2020/04/16/interna-brasil,845230/governadordo-maranhao-dribla-governo-federal-e-compra-mascaras-da-chi.shtml. Acesso em: 22 abr. 2020.
} 
DIL, Gabriel; GALLAS, Mirelle. A (i)legitimidade de atuação dos governos estaduais e municipais para o combate ao covid-19. Revista Eletrônica Direito e Política, Programa de Pós-Graduação Stricto Sensu em Ciência Jurídica da UNIVALI, Itajaí, v.15, n.2, 20 quadrimestre de 2020. Disponível em: www.univali.br/direitoepolitica - ISSN 1980-7791

respiradores. Assim que os equipamentos chegaram já os conectamos para ampliar a nossa oferta de leitos de UTI" 31 .

Dessa forma, constata-se que os governos estaduais e municipais, no que tange aos decretos e atitudes referentes ao enfrentamento da pandemia da Covid-19, encontram-se constitucionalmente amparados e legitimados pelo artigo 23, inciso II da Constituição da República Federativa do Brasil.

\section{A AÇÃo DIRETA DE INCONSTITUCIONALIDADE No 6.341 E A COMPETÊNCIA CONCORRENTE DE ESTADOS, DISTRITO FEDERAL, MUNICÍPIOS E UNIÃO NO COMBATE À COVID-19}

No contexto dos desafios de contenção da pandemia da Covid-19, os cientistas seguem com pesquisas a fim de descobrirem um fármaco capaz de curar as vítimas contaminadas pelo vírus, bem como buscam a descoberta de uma vacina que proteja a humanidade dessa nova doença. O vírus foi registrado pela primeira vez na China, no final de 2019. Posteriormente, o vírus começou a se alastrar velozmente pela Europa, Ásia, e finalmente chegou à América Latina, alarmando os Estados e exigindo que os governos iniciassem a tomada de medidas para combater o avanço da pandemia $^{32}$.

Desse modo, considerando a urgência humanitária em nível global, os Estados começaram a editar normas e regulamentações para definir quais políticas seriam tomadas para prevenir e erradicar a pandemia dentro de seus territórios. No Brasil, quando a pandemia ainda estava em fase embrionária, o presidente da república Jair Bolsonaro - negou por diversas vezes a gravidade iminente que o país adentrava. No entanto, com o avançar da doença, e com os alertas emitidos pela Organização Mundial da Saúde e pela postura tomada pelos demais chefes de Estado, Bolsonaro

\footnotetext{
${ }^{31}$ Governador do Maranhão dribla Governo Federal e compra máscaras da China. Correio Braziliense. Brasília/DF, 16 de abr. $2020 . \quad$ Disponível em: https://www.correiobraziliense.com.br/app/noticia/brasil/2020/04/16/interna-brasil,845230/governadordo-maranhao-dribla-governo-federal-e-compra-mascaras-da-chi.shtml. Acesso em: 22 abr. 2020

${ }^{32}$ Coronavírus: como é Wuhan, a cidade chinesa onde surgiu a epidemia de coronavírus e que foi isolada. BBC G1. São Paulo/SP, 23 de jan. de 2020. Disponível em: https://g1.globo.com/ciencia-esaude/noticia/2020/01/23/coronavirus-como-e-wuhan-a-cidade-chinesa-onde-surgiu-a-epidemia-decoronavirus-e-que-foi-isolada.ghtml. Acesso em: 15 abr. 2020.
} 
DIL, Gabriel; GALLAS, Mirelle. A (i)legitimidade de atuação dos governos estaduais e municipais para o combate ao covid-19. Revista Eletrônica Direito e Política, Programa de Pós-Graduação Stricto Sensu em Ciência Jurídica da UNIVALI, Itajaí, v.15, n.2, 20 quadrimestre de 2020. Disponível em: www.univali.br/direitoepolitica - ISSN 1980-7791

alterou o tom e começou a agir, ainda que minimamente, no combate da disseminação do vírus.

O Estado brasileiro decretou estado de emergência em meio a encontros e desencontros causados pelo presidente da república e seu respectivo ministro da saúde - Luís Henrique Mandetta -, onde o primeiro negava a gravidade da doença, se pronunciando no sentido de que a Covid-19 era uma "gripezinha" e deveria ser tratada como um "resfriadinho", enquanto o segundo emitia pareceres técnicos contrários a conduta do presidente, em que ratificava o enunciado pela Organização Mundial da Saúde 33 .

O discurso primário do presidente da república aos seus eleitores era de que, com a ampla cobertura da mídia brasileira, no que tange a gravidade da pandemia, a imprensa estaria sendo demasiadamente "alarmista" e exagerada, e estava se utilizando da pauta para o perseguir e comprometer a sua governabilidade ${ }^{34}$. A negação do presidente e a predominância técnica sanitária do discurso de Mandetta, provocou uma ruptura no governo, que acabou levando este a exoneração por não aderir ao discurso negacionista do presidente.

No entanto, embora a dissonância do discurso bolsonarista com a realidade experimentada no Brasil e no mundo, o presidente iniciou a tomada de uma série de medidas no combate a evolução da propagação da Covid-19 em território nacional, ainda que tardiamente, em comparação a países asiáticos por exemplo. Nesse sentido, no dia 06 de fevereiro de 2020, foi sancionada pelo presidente a Lei no 13.979, que "Dispõe sobre as medidas para enfrentamento da emergência de saúde pública de importância internacional decorrente do coronavírus responsável pelo surto de $2019^{\prime \prime 35}$.

33 OHANA, Victor. Bolsonaro debocha de epidemia do coronavírus no Brasil: "Gripezinha". Carta Capital, 20 de mar. de 2020. Disponível em: https://www.cartacapital.com.br/politica/bolsonaro-debocha-deepidemia-do-coronavirus-no-brasil-gripezinha/. Acesso em: 15 abr. 2020.

${ }^{34}$ Bolsonaro volta a minimizar crise de coronavírus: "Alarmismo da mídia". Carta Capital, 22 de mar. de 2020. Disponível em: https://www.cartacapital.com.br/saude/bolsonaro-volta-a-minimizar-crise-decoronavirus-alarmismo-da-midia/. Acesso em: 17 abr. 2020.

35 BRASIL. Decreto-lei no 13.979, de 06 de fevereiro de 2020. Disponível em: http://www.planalto.gov.br/ccivil_03/_ato2019-2022/2020/lei/L13979compilado.htm. Acesso em: 20 abr. 2020. 
DIL, Gabriel; GALLAS, Mirelle. A (i)legitimidade de atuação dos governos estaduais e municipais para o combate ao covid-19. Revista Eletrônica Direito e Política, Programa de Pós-Graduação Stricto Sensu em Ciência Jurídica da UNIVALI, Itajaí, v.15, n.2, 20 quadrimestre de 2020. Disponível em: www.univali.br/direitoepolitica - ISSN 1980-7791

A lei supramencionada estabelece a diferença entre "isolamento" e "quarentena", bem como dispõe acerca de quais condutas poderão ser tomadas pelas autoridades públicas enquanto perdurar os efeitos da pandemia da Covid-19. O texto da nova lei apresenta dispositivos que restringem em parte os direitos de liberdade em face da preponderância do direito coletivo e da preservação da saúde pública. Igualmente, a legislação excepcional versa também sobre a dispensa temporária de licitação para aquisição de bens e serviços necessários à manutenção do serviço de saúde.

Na vigência da lei que decretou a emergência da saúde pública brasileira, o presidente da república, invocando o artigo 62 da Constituição da República Federativa do Brasil promulgada em 1988, publicou a Medida Provisória no 926, no dia 20 de março de 2020, a qual altera alguns dispositivos da Lei 13.979/2036. O artigo 62 da Constituição Federal, estabelece que "Em caso de relevância e urgência, o Presidente da República poderá adotar medidas provisórias, com força de lei, devendo submetê-las de imediato ao Congresso Nacional" ${ }^{37}$.

A pandemia da Covid-19 reconhecida pela Organização Mundial da Saúde, bem como diante da emergência em que se encontra o sistema de saúde brasileiro, o qual apresenta déficit de leitos de unidade de tratamento intensivo, serve como fundamento razoável para que o Poder Executivo adote políticas rápidas por meio de medidas provisórias. Ademais, a Medida Provisória no 926, procedeu a alteração de alguns dispositivos previstos na Lei 13.979/20. Tais alterações via medida provisória se tornaram objeto da Ação Direta de Inconstitucionalidade no 6.341, proposta pelo Partido Democrático Trabalhista, perante o Supremo Tribunal Federal, no dia 23 de março de 2020.

Acrescenta-se que, no que concerne a intervenção do Poder Judiciário em atos determinados por autoridades majoritariamente eleitas pelo povo, por meio de ação direta de inconstitucionalidade, quando provocado, nada mais é do que um exercício

\footnotetext{
${ }^{36}$ BRASIL. Medida Provisória no 926, de 20 de março de 2020. Diário Oficial da República Federativa do Brasil, Poder Executivo, Brasília, DF. Disponível em: http://www.planalto.gov.br/ccivil_03/_ato20192022/2020/Mpv/mpv926.htm. Acesso em: 20. abr. 2020.

37 BRASIL. Constituição da República Federativa do Brasil promulgada em 05 de outubro de 1988. Disponível em: http://www.planalto.gov.br/ccivil_03/constituicao/ConstituicaoCompilado.htm. Acesso em: 20 abr. 2020.
} 
DIL, Gabriel; GALLAS, Mirelle. A (i)legitimidade de atuação dos governos estaduais e municipais para o combate ao covid-19. Revista Eletrônica Direito e Política, Programa de Pós-Graduação Stricto Sensu em Ciência Jurídica da UNIVALI, Itajaí, v.15, n.2, 20 quadrimestre de 2020. Disponível em: www.univali.br/direitoepolitica - ISSN 1980-7791

de reflexão democrática ${ }^{38}$. Uma instituição de tipo judicial não é uma câmara de representantes, funcionalmente pluralista, nem um governo estruturalmente partidário. O Poder Judiciário deve atuar para que o Poder Executivo e Legislativo cumpram corretamente com suas respectivas tarefas. Ainda, o Poder Judiciário teria um poder de admoestação e capacidade de iniciar processos judiciais contra agentes públicos considerados culpados, bem como recomendar a revogação de leis contrárias à Constituição, como é o caso aqui evidenciado, em que o Supremo Tribunal Federal foi provocado a fim de decidir acerca da constitucionalidade de uma medida provisória emanada pelo presidente da república ${ }^{39}$.

O PDT ajuizou a ADI buscando a declaração da incompatibilidade parcial da Medida Provisória no 926, com a Constituição Federal, em relação às alterações promovidas no artigo 30, caput, incisos I, II, e VI, e parágrafos 80, 90, 10 e 11 da Lei federal no $13.979 / 20^{40}$. O requerente arguiu a inconstitucionalidade formal em razão de que a matéria disciplinada por medida provisória deveria ser reservada a lei complementar. Alegou também o Partido político que a Medida Provisória no 926, viola a autonomia dos entes da Federação, postulando "o afastamento da exclusividade da União para dispor sobre as referidas providências" ${ }^{\prime 1}$.

Nesse sentido, o autor da ADI se utilizou do artigo 23, inciso II, combinado com os artigos 198, inciso I, e 200, inciso II, todos da Constituição da República Federativa do Brasil para fundamentar a inconstitucionalidade da Medida Provisória no 926, a fim de obter resposta da Suprema Corte brasileira no que tange a competência concorrente da União, Distrito Federal, Estados e municípios para disporem sobre medidas sanitárias a serem implementadas por cada ente da federação.

\footnotetext{
38 ROSANVALLON, Pierre. La legitimidad democrática: Imparcialidad, reflexividad y proximidad. Editora: Ediciones Paidós, 18 de mar. de 2010. p. 204.

${ }^{39}$ ROSANVALLON, Pierre. La legitimidad democrática: Imparcialidad, reflexividad y proximidad. p. 219.

40 BRASIL. Supremo Tribunal Federal. Ação Direta de Inconstitucionalidade no 6.341. Ajuizado pelo Partido Democrático Trabalhista (PDT) em face da Medida Provisória no 926 de 20 de março de 2020. Relator: ministro Marco Aurélio Mello. Brasília-DF. Disponível em: http://redir.stf.jus.br/estfvisualizadorpub/jsp/consultarprocessoeletronico/ConsultarProcessoEletronico.jsf ?seqobjetoincidente $=5880765$. Acesso em: 20 abr. 2020.

41 BRASIL. Supremo Tribunal Federal. Ação Direta de Inconstitucionalidade no 6.341. Ajuizado pelo Partido Democrático Trabalhista (PDT) em face da Medida Provisória no 926 de 20 de março de 2020. Relator: ministro Marco Aurélio Mello. Brasília-DF. Disponível em: http://redir.stf.jus.br/estfvisualizadorpub/jsp/consultarprocessoeletronico/ConsultarProcessoEletronico.jsf ?seqobjetoincidente $=5880765$. Acesso em: 20 abr. 2020.
} 
DIL, Gabriel; GALLAS, Mirelle. A (i)legitimidade de atuação dos governos estaduais e municipais para o combate ao covid-19. Revista Eletrônica Direito e Política, Programa de Pós-Graduação Stricto Sensu em Ciência Jurídica da UNIVALI, Itajaí, v.15, n.2, 20 quadrimestre de 2020. Disponível em: www.univali.br/direitoepolitica - ISSN 1980-7791

Ainda, o texto do artigo 23, inciso II da Constituição Federal é objetivo e não abre margem para interpretação que seja contrária ao entendimento de que há competência comum de todos os entes da federação no que tange ao cuidado da saúde e da assistência pública dos brasileiros ${ }^{42}$. Igualmente, o artigo 198, inciso I, também presente na Constituição Federal, dispõe acerca da descentralização, com direção única em cada esfera de governo, no que concerne as ações e serviços de saúde pública.

Entretanto, o artigo $3^{\circ}$ da Medida Provisória no 926/20 impugnado pelo Partido Democrático Trabalhista, na ADI no 6.341, não contraria o texto constitucional, uma vez que o disposto não afasta a competência concorrente da União, Distrito Federal, Estados e municípios para adotarem medidas sanitárias de contenção a propagação da Covid-19 dentro de suas respectivas áreas, de forma autônoma. Também, a adoção da medida provisória como meio de disciplinar a matéria não consiste em abuso de direito, muito menos em vício formal, uma vez que se está diante de um quadro de urgência internacional.

Nesse sentido, o relator Marco Aurélio Mello, em sede de apreciação de medida cautelar na respectiva ADI, declarou que

Vê-se que a medida provisória, ante quadro revelador de urgência e necessidade de disciplina, foi editada com a finalidade de mitigar-se a crise internacional que chegou ao Brasil, muito embora no território brasileiro ainda esteja, segundo alguns técnicos, embrionária. Há de ter-se a visão voltada ao coletivo, ou seja, à saúde pública, mostrando-se interessados todos os cidadãos. O artigo $3^{\circ}$, cabeça, remete às atribuições, das autoridades, quanto às medidas a serem implementadas. Não se pode ver transgressão a preceito da Constituição Federal. As providências não afastam atos a serem praticados por Estado, o Distrito Federal e Município considerada a competência concorrente na forma do artigo 23, inciso II, da Lei Maior. Também não vinga o articulado quanto à reserva de lei complementar. Descabe a óptica no sentido de o tema somente

42 BRASIL. Constituição da República Federativa do Brasil promulgada em 05 de outubro de 1988. Disponível em: http://www.planalto.gov.br/ccivil_03/constituicao/ConstituicaoCompilado.htm. Acesso em: 20 abr. 2020. 
DIL, Gabriel; GALLAS, Mirelle. A (i)legitimidade de atuação dos governos estaduais e municipais para o combate ao covid-19. Revista Eletrônica Direito e Política, Programa de Pós-Graduação Stricto Sensu em Ciência Jurídica da UNIVALI, Itajaí, v.15, n.2, $2^{\circ}$ quadrimestre de 2020. Disponível em: www.univali.br/direitoepolitica - ISSN 1980-7791

poder ser objeto de abordagem e disciplina mediante lei de envergadura maior.

Presentes urgência e necessidade de ter-se disciplina geral de abrangência nacional, há de concluir-se que, a tempo e modo, atuou o Presidente da República - Jair Bolsonaro - ao editar a Medida Provisória. O que nela se contém - repita-se à exaustão não afasta a competência concorrente, em termos de saúde, dos Estados e Municípios. Surge acolhível o que pretendido, sob o ângulo acautelador, no item a.2 da peça inicial, assentando-se, no campo, há de ser reconhecido, simplesmente formal, que a disciplina decorrente da Medida Provisória no 926/2020, no que imprimiu nova redação ao artigo 30 da Lei federal no 9.868/1999, não afasta a tomada de providências normativas e administrativas pelos Estados, Distrito Federal e Municípios ${ }^{43}$.

A decisão monocrática foi mantida pelo Plenário do Supremo Tribunal Federal, por unanimidade, no dia 15 de abril de 2020, tendo a Suprema Corte confirmado o entendimento "de que as medidas adotadas pelo Governo Federal na Medida Provisória (MP) 926/2020 para o enfrentamento do novo coronavírus não afastam a competência concorrente nem a tomada de providências normativas e administrativas pelos estados, pelo Distrito Federal e pelos municípios" ${ }^{44}$.

Por fim, conclui-se que a Medida Provisória no 926 que alterou alguns dispositivos previstos na Lei no 13.979/2020 não transgrediu a norma, muito menos violou preceitos estabelecidos pela Constituição Federal, tanto no âmbito formal, quanto material. A excepcionalidade experimentada neste período de pandemia, bem como a urgência de tomada de decisões para conter a propagação do vírus, são elementos de amparo da constitucionalidade da MP 926/20, bem como tal Medida Provisória não

\footnotetext{
${ }^{43}$ BRASIL. Supremo Tribunal Federal. Medida Cautelar na Ação Direta de Inconstitucionalidade no 6.341. SAÚDE - CRISE - CORONAVÍRUS - MEDIDA PROVISÓRIA - PROVIDÊNCIAS - LEGITIMAÇÃO CONCORRENTE. Surgem atendidos os requisitos de urgência e necessidade, no que medida provisória dispõe sobre providências no campo da saúde pública nacional, sem prejuízo da legitimação concorrente dos Estados, do Distrito Federal e dos Municípios. p. 05. Disponível em: http://redir.stf.jus.br/paginadorpub/paginador.jsp?docTP=TP\&docID $=752333455 \&$ prcID $=5880765 \&$ ad $=\mathrm{s}$ \#. Acesso em: 20 abr. 2020.

${ }^{44}$ SUPREMO TRIBUNAL FEDERAL. STF reconhece competência concorrente de estados, DF, municípios e União no combate à Covid-19. Imprensa do STF. Brasília/DF. Disponível em: http://portal.stf.jus.br/noticias/verNoticiaDetalhe. asp?idConteudo=441447\&ori=1. Acesso em: $20 \mathrm{abr}$. 2020.
} 
DIL, Gabriel; GALLAS, Mirelle. A (i)legitimidade de atuação dos governos estaduais e municipais para o combate ao covid-19. Revista Eletrônica Direito e Política, Programa de Pós-Graduação Stricto Sensu em Ciência Jurídica da UNIVALI, Itajaí, v.15, n.2, 20 quadrimestre de 2020. Disponível em: www.univali.br/direitoepolitica - ISSN 1980-7791

deve ser interpretada como violação da autonomia dos entes federados, ressaltandose a preponderância do disposto no artigo 23, inciso II da Constituição Federal, que atribui competência concorrente entre União, Distrito Federal, estados e municípios, portanto, podendo disciplinar e normatizar medidas de combate ao coronavírus.

\section{CONSIDERAÇÕES FINAIS}

A Constituição da República Federativa do Brasil respalda as competências concorrentes dos entes federativos a participação financeira e executora de ações e prestações de serviços em saúde. A autonomia dos entes federados e a descentralização das decisões é plenamente justificável em decorrência da própria competência concorrente atribuída pelo art. 23, inciso II, da Constituição Federal.

Com efeito, tratando-se de situação de extrema excepcionalidade e que visa a proteção da saúde da população, a atuação dos entes federados em todos os níveis é medida que se impõe nesse momento de caos pandêmico. A atuação dos estados e municípios com vistas a preservar a disseminação do vírus nas populações locais, poderá diminuir o volume de pessoas hospitalizadas, possibilitando que o sistema ùnico de Saúde atenda a contaminação em massa de forma mais adequada à realidade nacional em suas diferentes regiões.

Diante disso a decisão do STF acerca da Ação Direta de Inconstitucionalidade no 6.341, proposta pelo Partido Democrático Trabalhista, perante o Supremo Tribunal Federal, no dia 23 de março de 2020 é acertada no que tange ao reconhecimento das competências federativas.

\section{REFERÊNCIAS DAS FONTES CITADAS}

BARACHO, José Alfredo de Oliveira. O princípio da subsidiariedade: conceito e evolução. Rio de Janeiro: Forense, 2003.

Bolsonaro volta a minimizar crise de coronavírus: "Alarmismo da mídia". Carta Capital, 22 de mar. de 2020. Disponível em: https://www.cartacapital.com.br/saude/bolsonaro-volta-a-minimizar-crise-decoronavirus-alarmismo-da-midia/. Acesso em: 17 abr. 2020. 
DIL, Gabriel; GALLAS, Mirelle. A (i)legitimidade de atuação dos governos estaduais e municipais para o combate ao covid-19. Revista Eletrônica Direito e Política, Programa de Pós-Graduação Stricto Sensu em Ciência Jurídica da UNIVALI, Itajaí, v.15, n.2, $2^{\circ}$ quadrimestre de 2020. Disponível em: www.univali.br/direitoepolitica - ISSN 1980-7791

BRASIL. Constituição da República Federativa do Brasil promulgada em 05 de outubro de $1988 . \quad$ Disponível em: http://www.planalto.gov.br/ccivil_03/constituicao/ConstituicaoCompilado.htm. Acesso em: 20 abr. 2020.

BRASIL. Decreto-lei no 13.979, de 06 de fevereiro de 2020. Disponível em: http://www.planalto.gov.br/ccivil_03/_ato2019-2022/2020/lei/L13979compilado.htm. Acesso em: 20 abr. 2020.

BRASIL. Medida Provisória no 926, de 20 de março de 2020. Diário Oficial da República Federativa do Brasil, Poder Executivo, Brasília, DF. Disponível em: http://www.planalto.gov.br/ccivil_03/_ato2019-2022/2020/Mpv/mpv926.htm. Acesso em: 20. abr. 2020.

BRASIL. Supremo Tribunal Federal. Ação Direta de Inconstitucionalidade $\mathrm{n}^{0} 6.341$. Ajuizado pelo Partido Democrático Trabalhista (PDT) em face da Medida Provisória no 926 de 20 de março de 2020. Relator: ministro Marco Aurélio Mello. Brasília-DF. Disponível

em: http://redir.stf.jus.br/estfvisualizadorpub/jsp/consultarprocessoeletronico/ConsultarPr ocessoEletronico.jsf?seqobjetoincidente=5880765. Acesso em: 20 abr. 2020.

BRASIL. Supremo Tribunal Federal. Medida Cautelar na Ação Direta de Inconstitucionalidade no 6.341. SAÚDE - CRISE - CORONAVÍRUS - MEDIDA PROVISÓRIA - PROVIDÊNCIAS - LEGITIMAÇÃO CONCORRENTE. Surgem atendidos OS requisitos de urgência e necessidade, no que medida provisória dispõe sobre providências no campo da saúde pública nacional, sem prejuízo da legitimação concorrente dos Estados, do Distrito Federal e dos Municípios. p. 05. Disponível em: http://redir.stf.jus.br/paginadorpub/paginador.jsp?docTP=TP\&docID $=752333455 \& p r c I$ $\mathrm{D}=5880765 \& \mathrm{ad}=\mathrm{s} \#$. Acesso em: 20 abr. 2020.

Coronavírus: como é Wuhan, a cidade chinesa onde surgiu a epidemia de coronavírus e que foi isolada. BBC G1. São Paulo/SP, 23 de jan. de 2020. Disponível em: https://g1.globo.com/ciencia-e-saude/noticia/2020/01/23/coronavirus-como-ewuhan-a-cidade-chinesa-onde-surgiu-a-epidemia-de-coronavirus-e-que-foiisolada.ghtml. Acesso em: 15 abr. 2020.

CORRALO, Giovani da Silva. Dimensões do poder: as federações e os direitos fundamentais. Justiça do Direito, Passo Fundo, 2011 v. 25 n. 2 Disponível em: <http://seer.upf.br/index.php/rjd/article/view/4001> Acesso em: 31 mar. 2020.

Giovani da Silva. O poder municipal na federação brasileira: reflexão sobre a autonomia municipal e o federalismo. História : Debates e Tendências, Passo Fundo , v. 15 n. 1, 2015. Disponível em: <http://seer.upf.br/index.php/rhdt/article/view/5281>. Acesso em 31 mar. 2020.

Governador do Maranhão dribla Governo Federal e compra máscaras da China. Correio Braziliense. Brasília/DF, 16 de abr. de 2020. Disponível em: https://www.correiobraziliense.com.br/app/noticia/brasil/2020/04/16/internabrasil,845230/governador-do-maranhao-dribla-governo-federal-e-compra-mascarasda-chi.shtml. Acesso em: 22 abr. 2020. 
DIL, Gabriel; GALLAS, Mirelle. A (i)legitimidade de atuação dos governos estaduais e municipais para o combate ao covid-19. Revista Eletrônica Direito e Política, Programa de Pós-Graduação Stricto Sensu em Ciência Jurídica da UNIVALI, Itajaí, v.15, n.2, $2^{\circ}$ quadrimestre de 2020. Disponível em: www.univali.br/direitoepolitica - ISSN 1980-7791

GÜELL, Oriol. OMS declara alerta internacional diante da expansão incontrolável do coronavírus. El País, Barcelona, Espanha, 30 de jan. de 2020. Disponível em: https://brasil.elpais.com/sociedade/2020-01-30/oms-declara-alerta-internacionaldiante-da-expansao-incontrolavel-do-coronavirus.html. Acesso em: 23 abr. 2020.

MOREIRA NETO, Diogo de Figueiredo. Curso de Direito Administrativo. 16. ed. Rio de janeiro: Forense, 2014.

O que é a OMS? Organização Pan-Americana da Saúde. Universidade de São Paulo - USP. Biblioteca Virtual de Direitos Humanos. Disponível em: http://www.direitoshumanos.usp.br/index.php/OMS-Organiza\%C3\%A7\%C3\%A3oMundial-da-Sa\%C3\%BAde/o-que-e-a-oms.html. Acesso em: 10 abr. 2020.

OHANA, Victor. Bolsonaro debocha de epidemia do coronavírus no Brasil: "Gripezinha". Carta Capital, 20 de mar. de 2020. Disponível em: https://www.cartacapital.com.br/politica/bolsonaro-debocha-de-epidemia-docoronavirus-no-brasil-gripezinha/. Acesso em: 15 abr. 2020.

OLIVEIRA, Marcelo; SABÓIA, Gabriel. Quarentena em São Paulo e no Rio: O que você pode e o que não pode fazer. UOL, São Paulo/SP, 25 de mar. de 2020. Disponível em: $\quad$ https://noticias.uol.com.br/saude/ultimasnoticias/redacao/2020/03/25/quarentena-em-sao-paulo-o-que-voce-pode-e-o-quenao-pode-fazer.htm. Acesso em: 22 abr. 2020.

PASSO FUNDO (Município). Decreto no 32, de 19 de março de 2020, Prefeitura de Passo Fundo, Passo Fundo/RS. Disponível em: http://www.pmpf.rs.gov.br/servicos/geral/multimidia/decreto_32_2020_coronavirus_ 20032020.pdf. Acesso em: 22 abr. 2020.

PILAU SOBRINHO, Liton Lanes. A comunicação e o direito à saúde. Tese doutorado em direito. São Leopoldo: Universidade do Vale dos Sinos, 2007. Disponível em: http://www.dominiopublico.gov.br/download/teste/arqs/cp072014.pdf. Acesso em: 02 abr.2020.

Liton Lanes. Direito à saúde: uma perspectiva constitucionalista. Passo Fundo: UPF, 2003. In: ALVES, Paulo Roberto Ramos; PILAU SOBRINHO, Liton Lanes; MORANDINI, Jaqueline. Do constitucionalismo sanitário ao Estatuto do Idoso: o direito à saúde como aquisição evolutiva e suas formas de efetivação = Of the sanitary constitutionalism of the Elderly Statute: the right to the health as evolutionary acquisition and their effectuate forms. Revista Brasileira de Ciências do Envelhecimento Humano, Passo Fundo, v.5, n.2, p. 141-149, jul./dez. 2008. Disponível em: <http://www.upf.br/seer/index.php/rbceh/article/view/345/255>. Acesso em: 02 Abr. 2020.

PROUDHON, P.-J. Do princípio federativo e a necessidade de reconstruir o partido da revolução. Lisboa: Colibri, 1996.Tradução: Francisco Trindade.

REALE, Miguel. Virtudes e riscos do federalismo. In: Política e direito. São Paulo: Saraiva, $2006 . \quad$ p. 18-19. Disponível em: <https://integrada.minhabiblioteca.com.br/\#/books/9788502137691/cfi/28!/4/4@0.0 0:0.00>. Acesso em: 31 mar. 2020. 
DIL, Gabriel; GALLAS, Mirelle. A (i)legitimidade de atuação dos governos estaduais e municipais para o combate ao covid-19. Revista Eletrônica Direito e Política, Programa de Pós-Graduação Stricto Sensu em Ciência Jurídica da UNIVALI, Itajaí, v.15, n.2, 20 quadrimestre de 2020. Disponível em: www.univali.br/direitoepolitica - ISSN 1980-7791

REZENDE, JM DE. EPIDEMIA, ENDEMIA, PANDEMIA, EPIDEMIOLOGIA. Revista de Patologia Tropical / Revista de Patologia Tropical , v. 27, n. 1, 11. p. 153-155.

RIO GRANDE DO SUL (Estado). Decreto no 55.154, de 10 de abril de 2020, Palácio Piratini, Porto Alegre/RS. Disponível em: https://estado.rs.gov.br/upload/arquivos//decreto-55-154-01abr2020.pdf. Acesso em: 22 abr. 2020.

ROSANVALLON, Pierre. La legitimidad democrática: Imparcialidad, reflexividad y proximidad. Editora: Ediciones Paidós, 18 de mar. de 2010. 290p.

SARLET, Ingo Wolfgang; MARINONI, Luiz Guilherme; MITIDIERO, Daniel. Curso de direito constitucional. 7. ed. São Paulo: Saraiva Educação, 2018.

SILVA, José Afonso da. Curso de direito constitucional positivo. 39. ed. São Paulo: Malheiros, 2016.

SIMÕES, Carlos. Curso de direito de serviço social. 2.ed. São Paulo: Cortez, 2008.

STF reconhece competência concorrente de estados, DF, municípios e União no combate à Covid-19. Imprensa do STF. Brasília/DF. Disponível em: http://portal.stf.jus.br/noticias/verNoticiaDetalhe.asp?idConteudo=441447\&ori=1. Acesso em: 20 abr. 2020.

TORRES, Silvia Faber. O princípio da subsidiariedade no direito público contemporâneo. Rio de Janeiro: Renovar, 2001.

ZIMMERMANN, Augusto. Teoria geral do federalismo democrático. 2. ed. Rio de Janeiro: Lumen Juris, 2005.

Recebido em: 02/05/2020

Aprovado em: 10/07/2020 